\begin{tabular}{|c|c|c|c|}
\hline \multirow{2}{*}{$\begin{array}{r}\text { Case Reports in } \\
\text { Gastroenterology }\end{array}$} & \multicolumn{2}{|c|}{ Case Rep Gastroenterol 2018;12:143-146 } & \multirow[b]{2}{*}{$\begin{array}{l}\text { Karger } \\
\text { Open access }\end{array}$} \\
\hline & $\begin{array}{l}\text { DOI: 10.1159/000488523 } \\
\text { Published online: April 20, } 2018\end{array}$ & $\begin{array}{l}\text { (c) } 2018 \text { The Author(s) } \\
\text { Published by S. Karger AG, Basel } \\
\text { www.karger.com/crg }\end{array}$ & \\
\hline & $\begin{array}{l}\text { This article is licensed under } \\
\text { International License (CC BY- }- \\
\text { Usage and distribution for comn }\end{array}$ & $\begin{array}{l}\text { nons Attribution-NonCommercia } \\
\text { ger.com/Services/OpenAccessLice } \\
\text { uires written permission. }\end{array}$ & \\
\hline
\end{tabular}

\title{
Giant Symptomatic Rectal Mucocele following Subtotal Colectomy
}

\author{
Romano Schneider Marko Kraljević Markus von Flüe Ida Füglistaler \\ Department of General Surgery, St. Claraspital AG, Basel, Switzerland
}

\section{Keywords}

Rectal mucocele $\cdot$ Subtotal colectomy $\cdot$ Stenosis $\cdot$ Endoscopy

\begin{abstract}
Introduction: Rectal mucoceles rarely occur and only a few cases are described in the literature. They usually appear after subtotal colectomy or Hartmann procedure originating from persisting rectal mucus production and simultaneous stenosis of the anal canal. Case Presentation: A 74-year-old female patient presented with the feeling of an abdominal growing mass. Complex medical history included a subtotal colectomy with an end ileostomy and a mucous fistula at the descending colon due to Crohn disease at the age of 16 years. MRI showed a massive dilatation of the remaining colon and the rectum. Endoscopy failed due to complete anal stenosis and stenosis of the descending colon at the stoma site. A total proctocolectomy was performed. The pathology report showed a dilated rectum and sigma with large amounts of partly calcified mucus. There was no evidence of dysplasia, malignan$c y$, or Crohn manifestation in the completely obliterated proximal colon and the anus. Conclusion: Our case report underlines the importance of active endoscopic surveillance of the remaining colon and rectum in patients with diverting stomas and inflammatory bowel disease in order to detect stenosis. If endoscopic control is not possible due to obliteration, surgical therapy must be discussed due to the risk of developing cancer.
\end{abstract}




\section{Introduction}

Mucoceles appear frequently in the appendix vermiformis or in the nasal sinuses. A rectal stump after colorectal surgery normally produces small amounts of mucus, and this mucus is excreted through the anus repeatedly. A rectal mucocele originates from simultaneous mucus production and stenosis at the anal level. When these two factors coexist, the lack of draining of the mucus through the anal canal leads to an increasing dilatation of the rectum. Cases of rectal mucoceles are rare and have been described after Hartmann procedure [1] and after subtotal colectomy [2,3]. Additionally, we found 1 case of rectal mucocele after hemorrhoidectomy in the literature [4]. In all described cases, the dilatation seems to originate from persisting rectal mucus production and simultaneous stenosis of the anal canal. We present a rare case of a giant rectal mucocele following subtotal colectomy.

\section{Case Presentation}

A 74-year-old female patient presented with the feeling of an abdominal growing mass and weight loss (approximatively $10 \mathrm{~kg}$ within the last 12 months) without rectal bleeding or abdominal pain. After a computed tomography (CT) scan the patient was referred to our hospital with the suspicion of a rectal tumor. Complex medical history included a subtotal colectomy with an end ileostomy and a mucous fistula at the descending colon due to Crohn disease at the age of 16 years. In the following years, the patient suffered from repeated ileus episodes and a laparotomy with adhesiolysis was performed in 2007. She never took any medication for her Crohn disease and no further manifestations of activity were observed. Clinical examination showed the patient in reduced general condition; the abdomen was soft and there was no pain during the palpation of the abdominal wall. Laboratory values were in the standard range.

The imaging in the CT scan was not conclusive, and therefore we performed magnetic resonance imaging (MRI) to confirm the suspicion of tumor and to allow staging. The MRI showed a massive dilatation of the remaining colon and the rectum without detection of a tumor at the anal level (Fig. 1). Lower endoscopy failed due to complete anal stenosis and obliteration of the descending colon at the stoma site.

The possible therapeutic options were discussed with the patient. She refused a restoration of the intestinal continuity so we decided to perform an abdominoperineal rectum resection. After laparotomy and adhesiolysis the whole sigma and rectum appeared massively dilated (Fig. 2). The rectosigmoid was resected until reaching the muscular pelvic floor. The ileostomy was newly created after resecting the approximatively last $5 \mathrm{~cm}$ of the ileum because of a prolapse. The anus was dissected carefully intersphincterically and the specimen was removed completely (Fig. 3). The perineum was closed tension free.

The postoperative course was uneventful. The patient was discharged to rehabilitation on the 13th postoperative day. The pathology report showed a dilated rectum and sigma with large amounts of partly calcified mucus. There was no evidence of dysplasia, malignancy, or Crohn manifestation in the completely obliterated proximal colon and the anus. 
Schneider et al.: Giant Symptomatic Rectal Mucocele following Subtotal Colectomy

\section{Discussion}

Our case report underlines the importance of active endoscopic surveillance of the remaining colon and rectum in patients with diverting stomas and inflammatory bowel disease in order to detect stenosis and prevent the formation of a mucocele. If endoscopic control is not possible due to obliteration, surgical therapy must be discussed due to the risk of developing cancer.

\section{Statement of Ethics}

The authors have no ethical conflicts to disclose.

\section{Disclosure Statement}

The authors have no conflicts of interest to disclose.

\section{References}

1 Creagh MF, Chan TY. Case report: rectal mucocele following Hartmann's procedure. Clin Radiol. 1991 May;43(5):358-9.

2 Appleton N, Day N, Walsh C. Rectal mucocoele following subtotal colectomy for colitis. Ann R Coll Surg Engl. 2014 Sep;96(6):e13-4.

3 Davies RS, Wright A, Walker SJ. Case report: pelvic mucocele after sub-total colectomy and rectal excision. Clin Radiol. 1995 Jul;50(7):499-500.

4 Hsu KF, Hsieh CB, Yu JC, Chan DC, Wu CC, Jin JS et al. Rare rectal mucocele mimic tumor following hemorrhoidectomy in an adult patient. Rev Esp Enferm Dig. 2011 May;103(5):276-7.
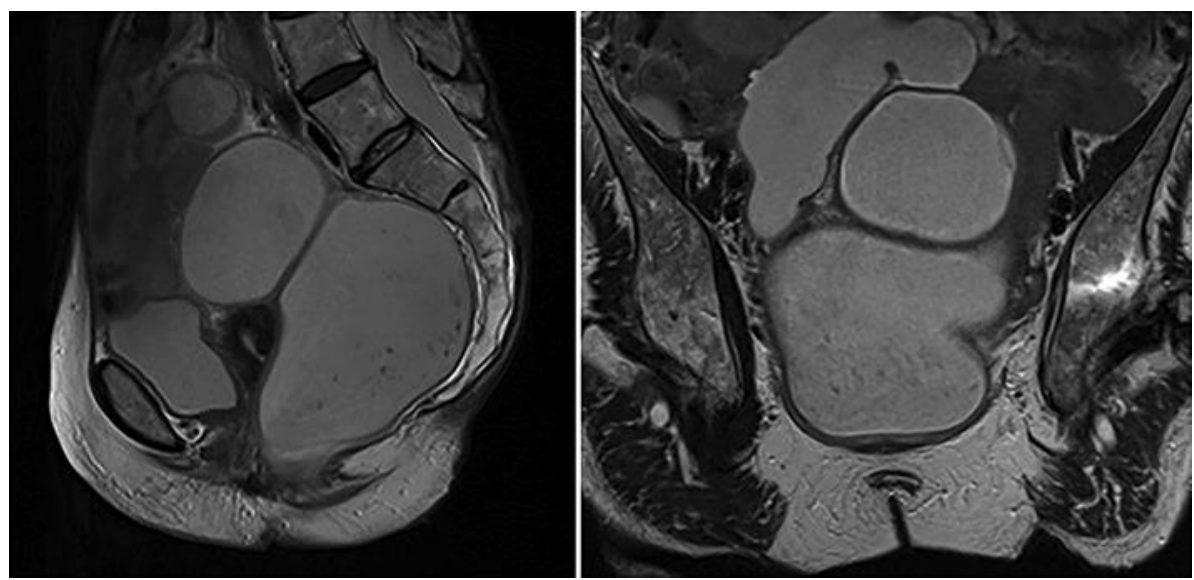

Fig. 1. Massive dilatation of the remaining colon and the rectum without detection of a tumor at the anal level (MRI, T2 series). 


\begin{tabular}{|c|c|c|}
\hline \multirow{2}{*}{$\begin{array}{l}\text { Case Reports in } \\
\text { Gastroenterology }\end{array}$} & \multicolumn{2}{|c|}{ Case Rep Gastroenterol 2018;12:143-146 } \\
\hline & DOI: 10.1159/000488523 & $\begin{array}{l}\text { O } 2018 \text { The Author(s). Published by S. Karger AG, Basel } \\
\text { www.karger.com/crg }\end{array}$ \\
\hline
\end{tabular}

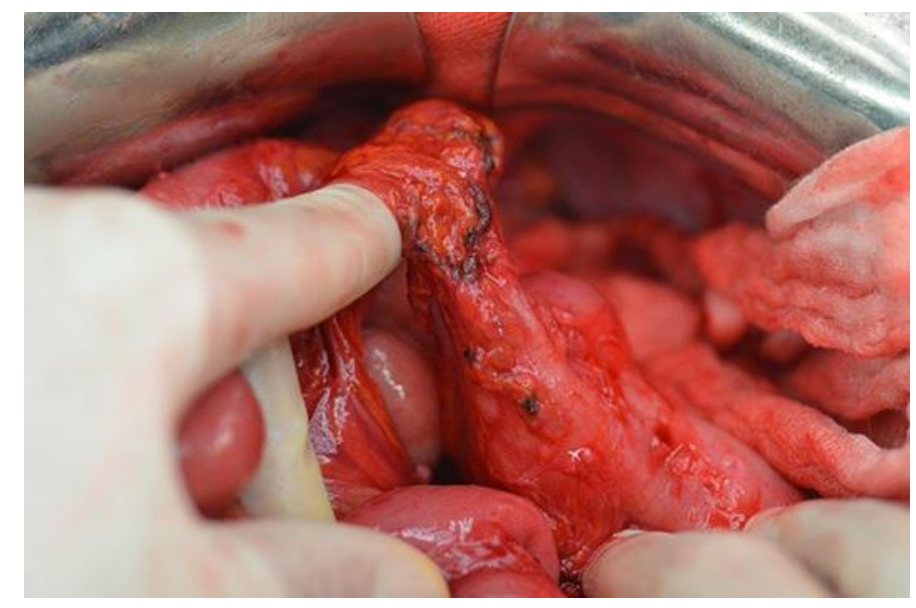

Fig. 2. Intraoperative picture of mucous fistula at the descending colon.

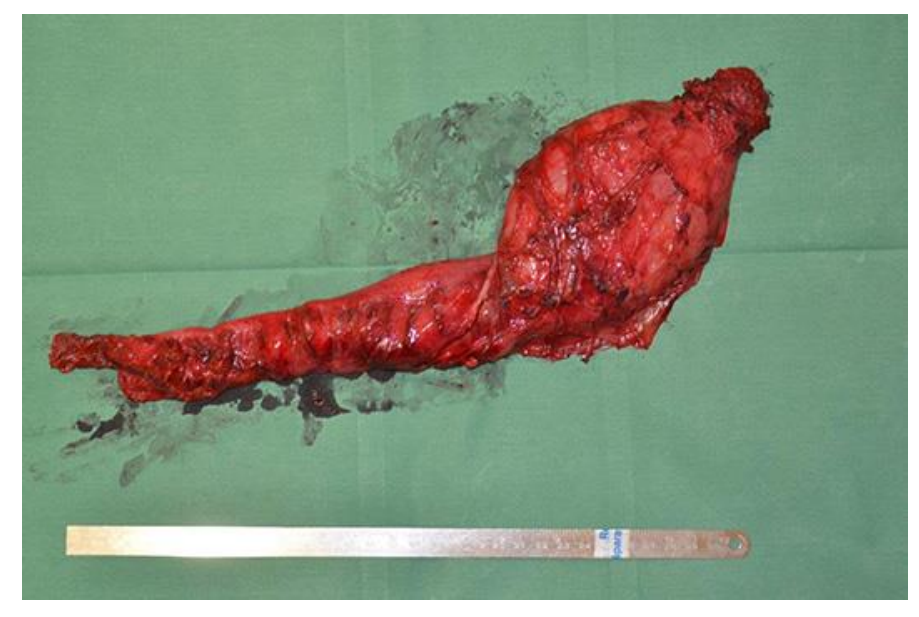

Fig. 3. Specimen of the abdominoperineal rectum resection. 